\title{
El conflicto de interpretaciones en torno a la recepción del Concilio Vaticano II
}

\author{
Eduardo Silva, S.J.*
}

La imagen de la batalla naval que utilizó Benedicto XVI para ilustrar lo que hasta ese momento eran los 40 años de interpretación del Concilio puede sorprender, parecer exagerada, pero no deja de reflejar lo mucho que se ha movido la barca de Pedro en estos años post-conciliares ${ }^{1}$.

Además no debería extrañar demasiado pues los conflictos en estos años de recepción no han sido mayores que los conflictos vividos en las cuatro sesiones de su realización y en los años de su preparación ${ }^{2}$. Pero el

Profesor de la Facultad de Teología de la UC y decano de la Facultad de Filosofía y Humanidades de la UAH.

1 San Basilio al describir la situación de la Iglesia después del Concilio de Nicea «la compara con una batalla naval en la oscuridad de la tempestad». Después de citarlo Benedicto concluye: "No queremos aplicar precisamente esta descripción dramática a la situación del pos-Concilio, pero refleja algo de lo que ha acontecido» (Benedicto XVI, mensaje a la curia del 22 de diciembre de 2005). Más allá del parecer de quienes estiman que ha sido justamente Benedicto quien ha contribuido a polarizar más el debate, al compararlo con una batalla, está muy lejos de ser el único en recurrir a esta metáfora. Así C. Pedotti titula su libro como $\mathrm{La}$ bataille du Vatican. 1959-1965 (Plon, Paris, 2011, 573 p.) y M. Faggioli el suyo comoVatican II, The Battle for meaning, 2012. Dos números especiales de revistas dedicadas al Concilio se titulan, respectivamente, "El Vaticano II: ¿un futuro olvidado?" (Concilium 312, septiembre 2005) y "Le Concile Vatican II en débat", en Recherches de Science Religieuse, janvier-mars 2012, tomo 100/1). Mientras P. Hünermann justifica su aporte en vistas a que «el debate deviene más virulento y provoca polarizaciones crecientes», G. Routhier sostiene que la interpretación del concilio deviene «un campo de batalla donde se despliegan escaramuzas que no están siempre a la altura de las esperas de los fieles o de las formas académicas» (respectivamente, en Recherche de Science Religieuse, janvier-mars 2012, tomo 100/1, 34 y 52).

2 Sabemos la anécdota contada por el propio Juan XXIII de que los cardenales recibieron su primer anuncio en enero de 1959 con un «silencio impresionante», 
conflicto se remonta todavía más atrás, pues ha atravesado todos los esfuerzos de renovación bíblica, patrística, litúrgica, pastoral del siglo XX, que se han abierto paso en medio de las condenas al modernismo, a los estudios bíblicos y a la Nouvelle Théologie. Paradigmática en este aspecto es la condena a la modernidad que hace el Syllabus, cien años antes del Concilio $^{3}$. Sin duda este conflicto de la Iglesia con el mundo es la clave que explica los conflictos al interior de la Iglesia, entre quienes estiman que es necesario seguir defendiéndose de un mundo hostil y quienes desean abrirse a este mundo que ya no es hijo de la Iglesia. Justamente la gran novedad de este Concilio, respecto de otros, es que no ha salido al paso de una herejía, sino que ha querido presentar el depósito de la $\mathrm{fe}$, de un modo adecuado según las exigencias de nuestro tiempo como lo señala Juan XXIII en el discurso inaugural. Para hablar con sus contemporáneos la Iglesia "prefiere usar la medicina de la misericordia más que de la severidad. Ella quiere venir al encuentro de las necesidades actuales, mostrando la validez de su doctrina más bien que renovando condenas» ${ }^{4}$. Es lo que se ha llamado el principio de pastoralidad del Concilio.

Por ello el Concilio no solo es el acontecimiento eclesial que se realizó durante cuatro años y el corpus textual sancionado, sino un conjunto mucho más vasto que incluye el tiempo anterior, incluida la renova-

preludio de lo que serán los sucesivos mensajes del Papa bueno respecto del futuro Concilio que parecen correr por canales paralelos a los preparativos que de él hacía la curia. La tensión que al comienzo de la primera sesión provoca el rechazo de las comisiones seguirá a lo largo de las cuatro sesiones y se explicitará en cada votación en la diferencia entre los votos aprobatorios de la mayoría y el rechazo de la minoría.

3 La teología neoescolástica, decimonónica, que reinaba antes del Concilio, era parte de los muros de defensa de una Iglesia Católica amurallada frente a los dos grandes embates que la acosaban: la reforma y la modernidad. Las heridas provocadas por la reforma, que habían nada menos que roto la cristiandad occidental y que habían llevado a las sangrientas guerras de religión, que solo la creación del Estado moderno logró aplacar, quizás ya no sangraban como antaño. Con todo, la única solución que la Iglesia Católica proponía, que los hijos que se habían alejado volvieran, no podía ser compartida por el movimiento ecuménico. Por su parte la modernidad era insistentemente condenada y el Syllabus era una no lejana prueba. Cada vez que un sacerdote se ordenaba u obtenía un grado en teología debía hacer el juramento antimodernista que introdujo Pío X en 1910; recién fue derogado en 1967. Los católicos debían ser antiecuménicos y antimodernos.

4 Juan XXIII, Gaudet Mater Ecclesia, discurso de apertura del 11 de octubre de 1962. 
ción eclesial que remotamente lo fue preparando y los años explícitos de preparación que comenzaron con el sorpresivo anuncio de Juan XXIII en 1959. Por tanto, una interpretación del Concilio debe ser capaz de considerar una hermenéutica del autor, una hermenéutica del texto y una hermenéutica de la recepción ${ }^{5}$. Esto significa que la hermenéutica conciliar comprende tres momentos: "la hermenéutica de los autores que reconstruye el contexto histórico de producción de los documentos conciliares; la hermenéutica de los textos que estudia su contenido por medio de un análisis literario, retórico y estructural; la hermenéutica de la recepción que se interesa en la Iglesia posconciliar con la diversidad de sus lugares y de sus etapas» ${ }^{6}$. Las interpretaciones variarán dependiendo si el énfasis se pone en el proceso conciliar, con toda su historia anterior (la intensión de sus autores), en los documentos conciliares mismos (el texto) o en la recepción del Concilio y sus documentos (en la interpretación que hacen los distintos lectores) ${ }^{7}$. Esta diversidad de énfasis es apreciable no solo en las diferentes aproximaciones individuales de los teólogos, sino también en los distintos momentos de la historia de esta recepción.

\section{Períodos en la ReCepción del ConCilio como clave hermenéutica}

Una periodización de estos 50 años nos da luces al respecto. Coincidimos con muchos intérpretes que un hito significativo que divide las aguas lo tenemos a los 20 años con la realización en 1985 del Sínodo extraordinario. Así podemos hablar de un primer periodo que se caracteriza por ciertos rasgos y de un segundo periodo de 30 años que tiene un momento de inflexión con el mensaje a la curia de Benedicto XVI del 22 de diciembre de 2005 con motivo de los 40 años del Concilio. Desde ese momento habría comenzado una segunda etapa de este segundo periodo. A partir del mensaje de Benedicto la polaridad fundamental, entre continuidad y discontinuidad, que el mismo había subrayado como Cardenal prefecto se distiende. De la misma manera sus polémicas de-

5 Cf. O. Rusch, Still Interpreting Vatican II. Some Hermeneutical Principles, (New York, Paulist Press 2004).

6 Ph. Borbeyne et L. Villemin (dir.), Vatican II et la théologie. Perspectives pour le XXIe siècle (Cerf, Paris 2006) 8.

7 O. Rusch, "Toward a comprehensive interpretation of the Council and its documenst», Theological Studies 73 (2012) 547-569. 
claraciones, justamente el mismo año del Sínodo, de que una verdadera interpretación del Concilio recién estaba comenzando, pueden ser mejor comprendidas a la luz de lo sucedido en los siguientes 20 años.

Pero más allá del protagonismo de Ratzinger, primero como Cardenal y luego como Papa, es posible ratificar esta periodización de estos 50 años justamente desde los esfuerzos hermenéuticos. La hermenéutica del Concilio, habiendo sido considerada como evidente en los primeros 20 años, llegara a ser objeto de reflexión en el curso de los años 80 . Un hito señero en esa reflexión que busca criterios para poder interpretar correctamente el Concilio es -como decíamos- el Sínodo extraordinario de 1985 convocado para celebrar, verificar y promover el Vaticano II: «hemos verificado unánimemente y con alegría el Concilio Vaticano II como expresión e interpretación legítima y válida del depósito de la fe, como se contiene en la Sagrada Escritura y en la viva tradición de la Iglesia». Esta extraña "validación» que un Sínodo episcopal se atreve a hacer de un Concilio ecuménico, este despropósito de pensar que un Concilio pudiera requerir una verificación de parte de un Sínodo es muy sorprendente. Podría explicarse en el esfuerzo por afirmar el Concilio frente a los críticos de derecha y a los de izquierda. Responde así a los que desconocen el Concilio, tanto los tradicionalistas exagerados (la ruptura conservadora) que ven en él un desvío del depósito, como los progresistas desmedidos (la ruptura progresista) que decepcionados por los escasos resultados, lo dan por superado. El problema no sería del Concilio (que pide una recepción auténtica, una verdadera interpretación) sino de estas falsas interpretaciones.

Los conflictos en la interpretación y recepción de Concilio eran por tanto inevitables. Tempranamente J. Ratzinger distingue «una fase de euforia (hasta 1968) y una fase de desilusión (1970-1980)» ${ }^{8}$. Dirá también que los años 80 representan un momento de síntesis y de equilibrio. $\mathrm{H}$. J. Pottmeyer complejiza este movimiento dialéctico alternando fuerzas innovadoras, luego las tendencias conservadoras para llegar a la síntesis que las retoma a ambas?. Siguiendo este trabajo, W. Kasper sostiene que

8 Cf. J. Ratzinger, Les Principes de la théologie catholique. Esquisse et matériaux, (Paris, Téqui, 1985. Original alemán de 1982).

9 Cf. H. J. Ротtmeyer, «Hacia una nueva fase de recepción de Vaticano II. Veinte años de hermenéutica», en G. Alberigo y J. P. Jossua (dir.), La recepción de Vaticano II (Cerf, Paris, 1985). 
«[...] podemos calificar la primera fase de la recepción como de expectativas excesivas. Se veía entonces el Concilio como un acontecimiento liberador. Muchos llegaron a pensar que el Vaticano II era un comenzar de cero y el punto de partida de una profunda dinámica conciliar [...] A esta fase tenía que seguir, casi por necesidad, la fase del desencanto. La desilusión tenía motivos diversos. Sin duda, no fueron satisfechas todas las expectativas legítimas especialmente en cuanto a la visión de la Iglesia como communio y a la colegialidad $»^{10}$.

Gilles Routhier termina reconociendo dos fases de recepción: la primera ocupada en la implementación que va significando el entusiasmo de unos y la decepción de otros, y la segunda que reflexiona sobre su interpretación a partir de los 80-85, que busca criterios de interpretación, que con más distancia procura reflexionar teológicamente sobre su significado. Un primer periodo pionero y un segundo periodo de "problematización hermenéutica». Así en la primera fase hay prácticas hermenéuticas pioneras, interpretaciones espontáneas o "no reflexivas», calificables de hermenéutica de la intención. Atendiendo al contexto histórico y a la historia de la redacción del texto, se ve su desarrollo y nos pone en contacto con la intención del autor, que da el sentido del texto, que por ello es transparente y claro. Además, como estos primeros comentadores eran a menudo los mismos actores del Concilio, para ellos el sentido del texto era inmediato y evidente. Practicas hermenéuticas que inducen a una cierta ruptura entre el antes y el después del Concilio. Una ruptura paradójicamente alentada por los círculos conservadores que se niegan a todo cambio. Ello pues la resistencia que oponen quienes no quieren modificar los textos elaborados en la fase preparatoria y su apego a la corta tradición neoescolástica, da un carácter revolucionario a la victoria de quienes reclaman una nueva manera de hablar y renovar la enseñanza. La insistencia en esta novedad, subraya el carácter de acontecimiento del Concilio y da valor «al espíritu del Vaticano II», que sin desvincularse de la letra de los textos, los comprende en relación a la historia del Concilio ${ }^{11}$.

10 W. Kasper, «El desafío permanente del Vaticano II. Hermenéutica de las aseveraciones del Concilio", en Teología e Iglesia (Ed. Herder, Barcelona 1989) 401-415.

11 Cf. G. Routhier, «L'herméneutique de Vatican II. Réflexions sur la face cachée d'un débat», en Recherche de Science Religieuse, 100/1 (2012) 47-50. 


\section{Hitos Y ASUNTOS CLAVE DEL SEGUNDO PERIODO}

La segunda fase que G. Routhier llama de "problematización hermenéutica», no ha sido más pacífica que la anterior. La búsqueda de criterios hermenéuticos, que le dan un carácter más reflexivo que la primera de aplicación más espontanea, no ha estado exenta de beligerancia. Lo podemos ver asomándonos brevemente a algunos hitos clave y destacables de este período ${ }^{12}$.

Partamos por recordar que el primer hito de este período, el Sínodo extraordinario de 1985, fue precedido de una polémica entrevista concedida por el entonces Cardenal Ratzinger a Vittorio Messori bajo el título Informe sobre la fe. En ella afloran todas las polémicas del periodo anterior, pues el Cardenal Ratzinger, se opone decididamente a hablar de "un antes y de un después (del Concilio) en la historia de la Iglesia», pues tal ruptura "es algo que no puede justificarse a partir de los documentos» ${ }^{13}$. Su juicio es lapidario sobre los primeros 20 años y sobre aquellos que ven en este acontecimiento un «nuevo pentecostés» o una verdadera revolución que invita a ir más allá del Concilio superándolo.

«Resulta incontestable que los últimos veinte años han sido decisivamente desfavorables para la Iglesia Católica. Los resultados que han seguido al concilio parecen oponerse cruelmente a las esperanzas de todos, comenzando por las del Papa Juan XXIII y después las de Pablo VI. Los Papas y los Padres conciliares esperaban una nueva unidad católica, y ha sobrevenido una división tal que, en palabras de Pablo VI, se ha pasado de la autocrítica a la autodestrucción. Se esperaba un nuevo entusiasmo, y se ha terminado con demasiada frecuencia en el hastío y el desaliento. Esperábamos un salto hacia adelante, y nos hemos encontrado ante un proceso de decadencia que se ha desarrollado en buena medida bajo el signo de un presunto "espíritu del Concilio", provocando de este modo su descrédito» ${ }^{14}$.

12 Seguimos en esto con libertad a Ch. Theobald que señala alguno de ellos en los apartados de la cuarta parte de su obra, «El débat sur la réception» $\mathrm{y}$ «Une bréve histoire de la reception de Vatican II", en La réception du concileVatican II. I. Accéder á la source (Cerf, Paris, 2009) 547-654.

13 J. Ratzinger - V. Messori, Informe sobre la fe (BAC, Madrid 1985) 41.

14 J. Ratzinger - V. Messori, Informe ... , 35-36. El Cardenal continúa: «Estoy convencido que los males que hemos experimentado en estos veinte años no se deben al Concilio "verdadero", sino al hecho de haberse desatado en el interior de la Iglesia ocultas fuerzas agresivas, centrífugas, irresponsables o simplemente 
De este diagnóstico pesimista el Cardenal concluye: «Creo que el tiempo verdadero del Vaticano II no ha llegado todavía, que su acogida auténtica aún no ha comenzado» ${ }^{15}$.

Esta entrevista y los juicios en ella emitida no son un hecho puntual, sino una posición mantenida durante todo el periodo, al punto que hemos dicho que su cierre lo podemos asociar a una nueva intervención del propio Ratzinger, ahora como pontífice el 2005. Algunos comentadores sostienen que este rol central jugado por el Cardenal Prefecto de la Sagrada Congregación de la Fe, se debe no solo a una toma de posición teórica y teológica, compartida por muchos, que se decanta en una serie de críticas a lo que estima desviaciones en la aplicación del Concilio, sino también al rol político que le ha tocado jugar frente al único grupo eclesial católico que no ha aceptado el Concilio. Consideramos como segundo hito relevante de este periodo los esfuerzos hechos por Roma para que los seguidores de Lefebvre vuelvan al seno de la Iglesia Católica. Ratzinger ha jugado un rol importante en los intentos de acercamiento con Mons. Lefebvre y la Fraternidad San Pío X, primero para evitar el cisma de Lefebvre que ocurrió cuando ordenó obispos y luego para llegar a un acuerdo con este grupo y poner los medios para que volviera al redil eclesial. En estas negociaciones ha sido partícipe fundamental el Cardenal, cuyo protagonismo excepcional en lo que a la interpretación del Concilio se refiere, se ha visto afectado por esta escaramuza política. Es la hipótesis que sostiene Routhier que lo señala como «una politización del debate» ${ }^{16}$, pues el esfuerzo "por imponer una determinada hermenéutica del Concilio ya no forma parte de la discusión académica, sino estaba subordinado a intereses políticos» ${ }^{17}$. Después de una primera fase de negociación, conducida por Seper, Lefebre envía a Juan Pablo

ingenuas, de un optimismo facil, de un énfasis en la modernidad, que ha confundido el progreso técnico actual con un progreso auténtico e integral. Y en el exterior, al choque con una revolución cultural: la afirmación en Occidente del estamento medio-superior, de la nueva "burguesía del terciario", con su ideología radicalmente liberal de sello individualista, racionalista y hedonista» 36-37.

15 J. Ratzinger - V. Messori, Informe ... , 46. Al respecto ver: L. Boeve, “"La vraie réception de vatican II n'a pas encore commencé”. Joseph Ratzinger, Révélation et autorité de Vatican II» en L'Autorité et les autotités. L'herméneutique théologique de Vatican II, sous la direction de G. Routhier et G. Jobin (Cerf, Paris, 2010) 13-50.

16 G. Routhier, «L'herméneutique de Vatican II. ... ,» 53-58.

17 G. Routhier, «L'herméneutique de Vatican II. ... ,» 58. 
II un proyecto de acuerdo (16 de octubre de 1980) que manifestaba su disposición a aceptar «el Concilio a la luz de la tradición». Lo suscribía a condición de aplicar «el criterio de la tradición a los diversos documentos del Concilio para saber qué es lo que hay que retener, lo que hay que aclarar, y lo que hay que rechazar» ${ }^{18}$. Esto significa que Lefevre ya no mantiene su postura inicial que sostenía que Vaticano II era una ruptura herética respecto de la Tradición anterior de 19 siglos. Ahora, poco después de la elección de Juan Pablo II, se ha convertido a una hermenéutica de la continuidad y está dispuesto a aceptar de Vaticano II lo que está en continuidad con esa tradición, pero rechazará lo que no lo está, como es el caso de la libertad religiosa. Por su parte Ratzinger confirma esa continuidad y rechaza las interpretaciones que pretendan sostener una ruptura con la tradición: hay continuidad. La pregunta del millón es quién interpreta a quién: ‘se interpreta el Concilio a la luz de la tradición o se interpreta la tradición desde la nueva luz alcanzada en el Concilio. Sería como aceptar de Trento solo lo que esté en consonancia con el Concilio de Florencia.

Un tercer hito lo tenemos en la producción y publicación en estos años de dos trabajos magistrales sobre el Concilio: la monumental historia dirigida por Giuseppe Alberigo y el comentario alemán de cinco tomos de Herder, dirigido por Peter Hünermann. En 1988 un equipo internacional ha resuelto que ya era posible realizar una historización rigurosa del Concilio y ha confiado el proyecto a G. Alberigo y al Instituto de Ciencias Religiosas de Bolonia. Apareciendo los primeros tomos en 1995, este trabajo colosal ha acabado en 2001 con la publicación italiana del quinto tomo La Storia del Concilio. Sin estar exento de polémica, particularmente en Italia por la crítica de A. Marcheto, el proyecto se ha realizado en un clima de tolerancia y apertura al pluralismo de perspectivas. Después de haber presentado sus criterios de interpretación del Concilio ${ }^{19}$, Alberigo "ha dejado a sus colaboradores un gran espacio de libertad en el tratamiento del tema que les ha confiado. Ha sido mi experiencia y también aquella de muchos otros colaboradores. Jamás

18 G. Routhier, «L'herméneutique de Vatican II. ... , " 56.

19 G. Alberigo, "Criterios hermenéuticos para una historia del Vaticano II», en J. Beozzo (ed.), Cristianismo e iglesias de América latina en vísperas del Vaticano II (San José Costa Rica, 1992) 19-31. 
hizo presión para que interpretáramos en un sentido determinado los acontecimientos que teníamos que cubrir» ${ }^{20}$.

Por su parte el comentario teológico germanófono dirigido por $\mathrm{P}$. Hünermann y Bernd Hilberath, el Herderstheologischer Kommentar zum zweitenvatikanischen Konzil, aparecido en 2005 y 2006, es una suerte de heredero de los tres volúmenes del Lexikonfür Theologie und Kirche (1966-1968) y esencialmente obra de una nueva generación. «Cada uno de los documentos conciliares es comentado según el orden cronológico y de manera muy detallada teniendo en cuenta la historia de su redacción ${ }^{21}$. El trabajo se completa con un quinto volumen, titulado Sintesis teológica y perspectivas, sobre el que volveremos al presentar los aportes teológicos de Hünermann.

Un cuarto hito lo constituyen las afirmaciones de Juan Pablo II en torno a la celebración del milenio, al indicar que el Concilio es «la gran gracia», "el gran acontecimiento del siglo XX» y «brújula segura» para orientarse en el siglo que viene. Lo consideramos un hito en el sentido que se trata, por así decirlo, de una nueva confirmación, de un nuevo reconocimiento durante el largo pontificado de Juan Pablo II, que el Concilio es justamente un acontecimiento mayor en la vida de la Iglesia y la hoja de ruta de esta comunidad. Son dos felices expresiones que dice en sus dos cartas apostólicas del jubileo del año 2000, Tercio milenio adveniente (10 de noviembre 1994) y Novo millennio ineunte (6 de enero 2001) en las que invita a los fieles a preguntarse sobre la recepción del Concilio. Estas palabras se conjugan con algunas «cimas» de recepción conciliar ocurridas durante el pontificado de Juan Pablo II y de Benedicto, como son el gesto de Asís (1986) y las encíclicas Ut unum sint (1995) y Deus caritas est (2006) que en palabras de Ch. Theobald «escapan a todo eclesiocentrismo y representan maneras originales de interpretar, en el contexto actual, la forma de la tradición cristiana ${ }^{22}$.

\footnotetext{
20 G. Routhier, «L'herméneutique de Vatican II. ... , " 52, nota 22.

21 Ch. Theobald, op. cit., 526. nt. 12.

22 Сн. Theobald, op. cit., 652.
} 


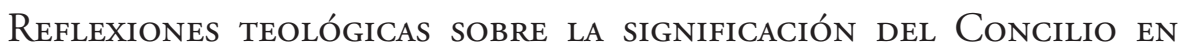
ESTE SEGUNDO PERIODO

Después del primer periodo pionero y de una primera etapa del segundo periodo de "problematización hermenéutica», que se ha visto marcado por los hitos mencionados, podemos observar el surgimiento de una serie de «nuevas aproximaciones», que superando las dialécticas y contraposiciones estériles buscan un principio de interpretación de la totalidad del acontecimiento conciliar, que incluye su realización, su corpus textual y los años de recepción ${ }^{23}$. Se trata de una serie de aportes teológicos muy significativos que aquí indicaremos brevemente: partiendo con el significativo aporte de Benedicto XVI, nos detendremos brevemente en las reflexiones teológicas de Peter Hünermann, Christoph Theobald y John O'Malley.

a) La hermenéutica de la reforma de Benedicto XVI

La polaridad excluyente entre una hermenéutica de la continuidad y una hermenéutica de la discontinuidad, la primera calificada simplemente de verdadera y la segunda de falsa y causante de todos los males imaginables -decíamos- se distiende en el mensaje de Benedicto el 2005 al mostrar, con tres ejemplos muy significativos, como la continuidad con la tradición, que siempre debe primar, se da en una cierta discontinuidad que las nuevas comprensiones y formulaciones del Concilio nos regalan.

«Precisamente en este conjunto de continuidad y discontinuidad en diferentes niveles consiste la naturaleza de la verdadera reforma. En este proceso de novedad en la continuidad debíamos aprender a captar más concretamente que antes que las decisiones de la Iglesia relativas a cosas contingentes -por ejemplo, ciertas formas concretas de liberalismo o de interpretación liberal de la Biblia- necesariamente debían ser contingentes también ellas, precisamente porque se referían a una realidad determinada en sí misma mudable. Era necesario aprender a reconocer que, en esas decisiones, solo los principios expresan el aspecto duradero, permaneciendo en el fondo y motivando la decisión desde dentro. En cambio, no son igualmente permanentes las formas concretas, que dependen de la situación histórica y, por tanto, pueden sufrir cambios. Así, las decisiones de fondo pueden seguir siendo

23 Cf. O. Rusch, «Toward a comprehensive interpretation of the Council..., , 547. 
válidas, mientras que las formas de su aplicación a contextos nuevos pueden cambiar» ${ }^{24}$.

La hermenéutica de la reforma ayuda a comprender esta relación. Al respecto son muy lúcidas las palabras de J. O’Malley.

«Benedicto XVI antes de ser elegido Papa, oponía de manera constante la hermenéutica de la ruptura (mala) y la hermenéutica de la continuidad (correcta), y lo hacía de una manera que parecía excluir toda vía media. En su discurso como Papa a la Curia romana, el 22 de diciembre del 2005, él en revancha ha opuesto una "hermenéutica de la ruptura" y una "hermenéutica de la reforma". Hay allí un cambio importante, que yo he notado como historiador, y que me parece muy oportuno ${ }^{25}$.

Después de citar las palabras de Benedicto XVI «Es precisamente en este conjunto de continuidad y de discontinuidad a diversos niveles que consiste la naturaleza de la verdadera reforma»- O’Malley concluye:

«En realidad todo lo que sucede en la vida forma 'este conjunto de continuidad y de discontinuidad', y el rol del historiador es discernir en qué punto lo uno y lo otro son operatorios. Es lo mismo para Vaticano II. Yo mismo estoy convencido que, allí comprendida la historia profana, los elementos de continuidad son más importantes que aquellos de la discontinuidad. La continuidad en la Iglesia -lo afirmo como católico- es más profunda que en la esfera no religiosa: ¡después de todo, la Iglesia no tiene ningún sentido, si ella falla en predicar el Evangelio, tal como es transmitido desde el origen! Esto no significa $\sin$ embargo que no haya discontinuidad $»^{26}$.

No ha sido fácil en el catolicismo darle carta de ciudadanía a la noción de reforma. Para defenderse de «la acusación de los protestantes de que la "Iglesia papal" se había desviado de las enseñanzas de la Escritura e ideado doctrinas no contenidas en ella» se insistió en la ininterrumpida continuidad con Cristo y los apóstoles. «La inmutabilidad se convirtió en el sello del catolicismo moderno» ${ }^{27}$. Más aún si los protestantes se apropiaron de la palabra reforma. Es este pavor al cambio lo que explica por ejemplo la reacción a la obra de Y. Congar de 1950 que tituló

\footnotetext{
24 Benedicto XVI, mensaje a la Curia del 22 de diciembre 2012.

25 J. O’Malley, Entrevista en La Croix. “L’ABC de Vatican II” (2012) 77-78.

26 J. O'Malley Idem.

27 J. O’Malley, «Ressourcement y reforma en el Vaticano II», Concilium (2012) 362.
} 
«Verdadera y falsa reforma en la Iglesia». Para abordar el problema del cambio los pensadores católicos, en los años de inauguración del Concilio usaban tres términos: aggiornamento, desarrollo y ressourcement. Si bien el primero surgió como el más a menudo utilizado, no era el más operativo en el Concilio. Este papel estaba reservado al desarrollo y al ressourcement. Según John Courtney Murray el «desarrollo doctrinal» era la cuestión subyacente a todas las demás del Concilio. Pero reivindicada ahora la noción de reforma, O’Malley concluye:

«En el corazón de la idea de reforma, hay la noción de cambio, cambio para lo mejor, lo que es la definición clásica de la reforma, "mutatio in melius". Pero la reforma no es un cambio que suprime lo que está en vías de cambiar. El Vaticano II ha intentado cambiar las cosas para mejor, como todos los concilios. En esto, puede ser llamado un concilio reformador. ¡Pero después del Concilio, la Iglesia Católica permanece identificable con la Iglesia Católica! ${ }^{28}$.

Una hermenéutica de la reforma permite afirmar la novedad, los aspectos nuevos que este Concilio nos regaló, sin por ello desconocer que está en continuidad con la bimilenaria historia de la Iglesia. Presento tres reflexiones teológicas recientes que interpretan el Concilio desde el punto de vista de su novedad.

b) El Concilio como una novedad en la historia de la Iglesia y como «texto constitucional de la fe» (Peter Hünermann)

La insistencia en la novedad ha sido una constante en la interpretación del Concilio. La famosa "Interpretación fundamental del Concilio" que hizo K. Rahner lo comparaba al paso dado por Pablo que lleva al cristianismo de ser una religión judía a la universalidad de los gentiles. Con el Vaticano II se da un segundo paso de esa envergadura, pues se pasa de ser una comunidad europea u occidental a una iglesia por primera vez universal.

Esta novedad está también en la concepción del Concilio como un acontecimiento. G. Routhier resume bien la postura de G. Alberigo al decir de ella que el Concilio es considerado en estas lecturas como «acontecimiento epocal que hace entrar a la Iglesia en un nuevo período de su historia, el Vaticano II se presenta como un momento de giro de

28 J. O’Malley, «Ressourcement y reforma..., , 362. 
la historia del catolicismo y su enseñanza debe ser interpretada en ese sentido ${ }^{29}$. P. Hünermann confronta la novedad de Concilio con hitos fundamentales de la historia de la Iglesia. Si recibir es hacer propio lo que se recibe, de manera que lo que se recibe me transforme al punto que se convierte en una nueva determinación del propio $\operatorname{ser}^{30}$, ¿qué debe recibir la Iglesia de hoy del Concilio? ¿Cuáles son las nuevas determinaciones del ser eclesial? ¿Cuál es el paso que ha dado el Concilio?, ¿qué ha dejado atrás esta iglesia peregrina? «¿De qué se despide, hacia dónde va?» ${ }^{31}$. Según P. Hünermann solo de estas preguntas surgirán los criterios para su recepción. Se trataría de buscar los puntos de referencia que determinan un punto de partida respecto del cual el Concilio implica una evolución, un cambio, una ruptura, una despedida. Analiza cuatro puntos de referencia que «tienen una estructura doble en sí mismos: son lugares históricos bien concretos de los que despedirse y a partir de los cuales se avanza hacia el futuro» ${ }^{32}$. En cada caso Hünermann indica la constitución, el decreto o la declaración del Concilio que permite apreciar la distancia con respeto a esa situación eclesial y se convierten en verdaderas señales visibles de que ya no estamos en ese momento. Así Gaudium et Spes pone fin a cien años de defensa férrea frente a la modernidad representada por Vaticano I; Unitatis redintegratio salda quinientos años de división de la iglesia en Occidente; la misma Unitatis redintegratio y Orientalium ecclesiarum se enfrenta con los más de mil años del cisma de Oriente; Dignitatis humanae es una novedad de proporciones frente a la iglesia estatal inaugurada por Constantino ${ }^{33}$. En cada caso se

29 G. Routhier, "L'herméneutique de Vatican II: de l'histoire de la rédaction des textes conciliares à la structure d'un corps", en G. Routhier, Vatican II. Herméneutique et réception (Ed. Fidei, Quebec, 2006) 391. Después de comentar la propuesta de Alberigo, examina también brevemente las de Hünerman, Theobald, la suya propia y la de O’Malley (391-399).

30 Cf. Hünermann, "Kriterenfür die Rezeption des II. Vatikanischen Konzils», en Theologische Quartalschrift 191 (2011) 126-147. Una reciente traducción y condensación de este articulo realizada por A. Funken en Hünermann, «Criterios para la recepción del Concilio Vaticano II», en Selecciones de teología (2012) 31-47.

31 Hünermann, «Criterios ... ,» 31.

32 HünermanN, «Criterios ..., , 32.

33 Los títulos de cada uno de los apartados nos dan una buen idea de lo que se trata: «1. Adiós a una eclesialidad estatal de 1.500 años. Dignitatis humanae es la señal visible de la ruptura; 2. Adiós a la escisión milenaria de la Iglesia oriental y occidental. La señal visible se encuentra tanto en OrientaliumEcclesiarum como 
describen los «rasgos fundamentales de la figura de la fe a la que se dice adiós» y las "características de un nuevo perfil» eclesial o las señales que indican un nuevo comienzo.

Con Vaticano II la Iglesia está en condiciones de superar el Vaticano I y su ruptura con la modernidad; Trento y la separación con los protestantes; el cisma y la separación con la Iglesia oriental y el edicto de Milán dejando de ser una iglesia estatal. Con ello nos ha provisto de nuevas determinaciones eclesiales. Al mostrar, por un lado, cuales son las instancias históricas o figuras de la fe y de la Iglesia de las que hay despedirse, y por otro, el nuevo punto de partida que los textos conciliares indican, "se muestra al mismo tiempo el "carácter constitucional de los documentos del Concilio Vaticano II". Queda bien claro qué apariencia histórica de la comprensión de la fe y de la Iglesia queda ya a la espalda y en qué dirección va el nuevo movimiento. Hablar del "carácter constitucional" de estos documentos no significa que se interprete el Concilio de forma jurídica» ${ }^{34}$.

Hünermann en trabajos anteriores ${ }^{35}$ ha reflexionado sobre las categorías «concilio y decisiones conciliares» profundizadas por la cuestión del discurso del Concilio Vaticano II como acontecimiento. Nos confiesa que el amplio comentario publicado por Herder y que se terminó el 2005, fue elaborado «a partir de estas premisas semánticas. Estos a priori formales, significativos estructurantes, han sido acogidos por todos los contribuidores que han participado en el comentario» ${ }^{36}$. El quinto volu-

en Unitatis redintegratio; 3. Adiós a 500 años de escisión en la iglesia de occidente. Señal bien visible en Unitatis redintegratio; 4. Despedida de más o menos un siglo de dudas por parte de la iglesia ante la modernidad; una buena muestra es el Vaticano I. Señal bien visible en Gaudium et spes».

HÜNERMANN, «Criterios ... , 46.

35 P. HÜnermann, "Zu den Kategorien "Konzil und Konzilsentscheidungen" -Vorüberlegungen zur Interpretatio des II. Vatikanums”, in P. Hünermann (ed.), Das II.Vatikanum - Christlicher Glaube im Horizont globaler Modernisierung. Einleitungsfragen, Paderborn 1998, 67-82.; P. HünERMAnn, "Das Vatikanum als Ereignis und die Fragenach seiner Pragmatik", in Das II.Vatikanum 107-125. Hay traducción castellana, "El Vaticano II como acontecimiento y la cuestión acerca de su pragmática”, en C. Schickendantz (ed.), A 40 años del Concilio Vaticano II. Lecturas e interpretaciones (Córdoba 2005) 125-160.

36 P. Hünermann, «Quo vadis? Au sujet de l'importance du concile pour l'Église, l'oecuménisme et la sociétéaujourd'hui», en Recherches de Science Religieuse 100/1 (2012) 35 . 
men de este gran comentario, que es una suerte de evaluación teológica de las cuestiones abiertas, las soluciones y las orientaciones, se abre con un primer capítulo de Hünermann ${ }^{37}$, en el que define el corpus de los textos del Vaticano II como un «texto constitucional de la fe». «En tanto que texto constitucional de la fe, tiene un carácter magisterial obligatorio, pero permanece también un texto fundamentalmente abierto, tributario de su traducción concreta en la praxis creyente del pueblo de Dios, del gobierno eclesial, del trabajo teológico-canónico, y de la formulación de reglas» ${ }^{38}$.

c) Principio de pastoralidad como clave del Concilio (Christoph Theobald)

Una clave de interpretación del Concilio es el principio de la pastoralidad: «un Concilio para abrir la Iglesia al mundo, retornando a su Tradición más auténtica». Una doble extroversión debida a su deseo de $a g$ giornamento (abrirse a los contemporáneos) mediante un ressourcement (vuelta a su fuente: la Palabra de Dios). Ch. Theobald en su amplísima obra sobre la recepción del Concilio hace del principio de pastoralidad la clave del Concilio y también «el motor secreto» del proceso de su recepción. Este principio formulado por Juan XXIII, acogido en el mismo Concilio, se manifiesta en la manera nueva de encontrarse con los otros. Su carácter ecuménico nos habla de una nueva manera de relacionarse con los hermanos separados. «Siendo entonces comprendido como principio pastoral y ecuménico, saca progresivamente sus implicaciones, primero la necesidad teologal de una reforma que toque todas las prácticas eclesiales, incluida la formulación de la doctrina, y luego toma en cuenta la situación histórica y cultural de los interlocutores de la Iglesia» ${ }^{39}$. Si pastoralidad es atención a los destinatarios, a los contemporáneos, al mundo de Dios, su clave está en la apertura a los otros. Pastoralidad es atención a la alteridad. «Para ser breves, es la interpretación teológica del misterio de la alteridad y de la manera de vivirlo lo que está en juego en este proceso de aprendizaje intraconciliar, sea que se trate de la alteridad

37 P. Hünermann, "Der Text: Werden - Gestalt - Bedeutung. Eine Hermeneutische Reflexion", in Herders Theologischer Kommentar zum ZweitenVatikanischen Konzil, hrsg. von H.J. Hilberath, P. Hünermann, 5 vols. (Freiburg i.B. 2004-2005) (HThK Vat II): vol. 5,5-101.

38 P. Hünermann, «Der Text: Werden - Gestalt - Bedeutung. ...» .

39 C. Theobald, La réception du concile Vatican II. I. Accéder á la source (Cerf, Paris, 2009) 543. 
en el seno mismo de la Iglesia Católica, en el mundo ecuménico, o más ampliamente, de la alteridad de religiones y de culturas en una civilización en vías de mundialización $»^{40}$. El misterio de la alteridad es la Palabra de Dios que llama y que invita a la comunidad cristiana a una doble escucha, a salir de sí misma para escuchar al Dios que habla en medio de los hombres de nuestro tiempo.

«En coherencia con este principio de pastoralidad, la manera de buscar la verdad en el seno mismo de la asamblea conciliar se inscribe progresivamente en un corpus textual cuyo eje vertical y eje horizontal suponen últimamente la experiencia de una doble escucha: la de la palabra de Dios y la que pasa en y entre los interlocutores más diversos. Es esta experiencia teologal que el corpus quiere hacer posible en todo la concreción en aquellos y aquellas, individuos y comunidades, que se prestan a la recepción $»^{41}$.

Principio de pastoralidad que implica una reforma eclesiológica, que coloca a la comunidad de los creyente en la doble atención a la Revelación y a los signos de los tiempos.

d) Un nuevo lenguaje (John O’Malley)

Una de las clásicas dicotomías en la historia de la Iglesia y que se ha usado para oponer interpretaciones en conflicto es la del espíritu y la letra. Frente al privilegio que algunos dan al acontecimiento, a un supuesto "espíritu del concilio", que sirve para decir cualquier cosa sobre él, otros oponen el corpus documental, los textos, lo que fue oficialmente aprobado y votado por la mayoría. Los textos en su integralidad, y no solo aquellos que me interesan o corresponden a mis intereses. En ese sentido no cabría hacer una lectura que dé más validez a los que recogen la novedad conciliar y menos a aquellos que se saben fueron textos de compromiso. Tampoco sería posible dar más validez a los textos de la mayoría por sobre aquellos que fueron introducidos por la minoría. Esta postura, que se pone a resguardo de los análisis del método histórico que permite seguir el desarrollo de un texto en las distintas etapas de su desarrollo conciliar, esta precaución frente a un privilegio diacrónico, no es incompatible con el privilegio sincrónico de quienes estiman que las constituciones tienen más centralidad que los decretos y declaraciones.

40 C. Theobald, La réception du concile Vatican II.... .
41 C. Theobald, La réception du concile Vatican II. ... . 
Así lo afirmó explícitamente el Sínodo extraordinario. Como sea, se trata de dar privilegio a los documentos, al texto, a la letra y no al acontecimiento y al espíritu del concilio. John O'Malley, da un giro interesante a esta dicotomía, en el sentido que señala que es justamente el lenguaje, el estilo, la retórica conciliar lo que constituye una novedad y que es lo más característico del Concilio: «al examinar la forma y el vocabulario, la "letra" llegamos al "espíritu"».

"Bien entendido, "el espíritu del Vaticano II" indica ciertas orientaciones de base que están expresadas de modo claro y no simplemente en uno o dos documentos del Concilio: se desarrollan casi del primero al último. Esto apunta al estilo en el cual estas indicaciones están formuladas. Por lo tanto, el espíritu está sólidamente basado en "la letra" en el más amplio sentido, lo que incluye tanto la forma como el fondo. Así entendido, la expresión desvela el sentido más amplio de la reunión conciliar ${ }^{42}$.

O'Malley sostiene que lo que da coherencia al conjunto tan vasto del corpus conciliar, es ante todo el estilo. Una retórica, que se asemeja al discurso de los Padres de la Iglesia y que se distingue de todos los textos conciliares anteriores al abandonar el lenguaje técnico y jurídico que los caracteriza ${ }^{43}$. Una nueva manera de caracterizada por el retorno a las fuentes, por no multiplicar las prescripciones, por una actitud de diálogo. Un Concilio de acercamiento y no de anatema que debe «usar la medicina de la compasión en vez de aquella de la severidad» como lo indicó Juan XXIII. «Es luego en su programación retórica más que en los enunciados ellos mismos que los textos conciliares se distinguen y manifiestan su coherencia» ${ }^{44}$.

Esto de que la mayor novedad del Concilio Vaticano II sea su modo de hablar, el uso de un lenguaje inédito, una manera de comunicarse con los contemporáneos parece corresponder a la intención de quien lo convocó. Efectivamente Juan XXIII en Gaudet Mater Ecclesia declara:

«Es necesario que esta doctrina, verdadera e inmutable, a la que se debe prestar fielmente obediencia, se profundice y exponga según las

42 J. O’Malley, «El Concilio del acercamiento», en Mensaje (612, septiembre 2012) 19.

43 Cf. J. O’Malley, «Erasmus and Vatican II: interpreting the Council», en A. Melloni et al., Cristianesimo nella storia. Saggi in onore di Giuseppe Alberigo (Bolgne, Il Molino, 1996) 195-222.

44 G. Routhier, Vatican II. Herméneutique et réception, ... , 399. 
exigencias de nuestro tiempo. En efecto, una cosa es el depósito de la fe, es decir, las verdades que contiene nuestra venerable doctrina, y otra distinta el modo como se enuncian estas verdades, conservando sin embargo el mismo sentido y significado».

Que la doctrina se «exponga según las exigencias de nuestro tiempo», que sea importante "el modo como se enuncian estas verdades», parece ser la clave que permite que viejas polaridades, dicotomías, dualismos puedan ser superados y se conviertan en dialécticas fecundas y productivas. Quizás estamos en condiciones de superar esas polaridades excluyentes, que $\mathrm{O}$. Rusch presenta como tensiones que enriquecen y que sintetiza brillantemente ${ }^{45}$. Análogo al modo como O’Malley piensa la unidad de la letra y del espíritu, al sostener que en este nuevo lenguaje está el espíritu del Concilio, está la superación de la dicotomía entre el acontecimiento conciliar y el corpus doctrinal. Pensar la unidad de la diferencia ha permitido también, como lo hemos visto superar la dualidad entre continuidad y discontinuidad en una hermenéutica de la reforma. La riqueza de este "cambio para lo mejor», permite aceptar que el hecho de que Vaticano II sea algo único entre todos los concilios no impide que esté en continuidad con todos ellos, justamente en la medida que los supera, cómo hemos visto que lo analiza P. Hünermann. También hemos visto cómo el principio de pastoralidad es el que permite superar una falsa oposición entre lo pastoral y lo doctrinal: el principio de pastoralidad o la orientación pastoral del Concilio, implica que las afirmaciones doctrinales (que las hay y son muchas) deben ser dichas de un modo comprensible para los contemporáneos. No se trata de que algunas sean afirmaciones doctrinales y otras pastorales, sino que todo, la doctrina incluida se dice pastoralmente.

La superación de dicotomías y dualismos en beneficio de tensiones que enriquecen es posible si se superan los dualismos de fondo. Los vemos aflorar por doquier cuando se opone contenido a forma o principios a formas de expresión. La afirmación de O’Malley de que la clave del Concilio está en la novedad de su lenguaje, que en esa nueva letra asoma el espíritu del concilio nos obliga a superar el dualismo que opone lo interior o lo exterior, lo de dentro a lo de fuera, el alma al cuerpo, valorando solo los primeros términos y relativizando los segundos. "No se puede afirmar la diferencia entre verdad, como contenido permanente, y

45 O. Rusch, «Toward a comprehensive interpretation of the Council ...» 547-569. 
lengua, como simple formulación. Semejante hermenéutica esencialista es demasiado poco consciente del círculo hermenéutico de toda comprensión humana y también teológica. La lengua y la historia son por lo menos co-constitutivas de la verdad $»^{46}$. Pensar la unidad de todas estas diferencias es lo que permite que sea posible articular las interpretaciones en conflicto sobre el Concilio Vaticano II.

A MODO DE CONCLUSIÓN: SUPERACIÓN DE LAS POLARIDADES EXCLUYENTES EN MEDIO DE LAS INTERPRETACIONES EN CONFLICTO

En estos 50 años de recepción del Concilio las interpretaciones en conflicto no han sido menores que las vividas durante su preparación y su realización. Al momento de interpretarlo no siempre resulta claro que es el Concilio y a que se debe dar primacía: a la intención de sus autores (que es posible descubrir cuando se indaga en la historia de su redacción); a los documentos y textos definitivos aprobados y sancionados; a la historia de los efectos provocados por el propio Concilio en el proceso de su recepción. Privilegiando la recepción del acontecimiento y de sus textos hemos hecho una periodización de estos 50 años, destacado algunos hitos clave y presentado algunas aproximaciones teológicas que nos parecen verdaderos aportes.

Hemos distinguido en la recepción del Concilio un primer periodo que termina con el Sínodo extraordinario de 1985. Los veinte primeros años se caracterizan por una interpretación más espontánea y menos reflexiva, por esfuerzos pioneros en los que participan también los propios actores del Concilio que consideran como evidente la intención conciliar, provocando el entusiasmo de unos y la decepción de otros. Los siguientes treinta años, en cambio, se empeñan en la búsqueda de criterios de interpretación, que implican una "problematización hermenéutica».

Hemos señalado una serie de hitos de este segundo periodo que nos parecen bastante determinantes para su recepción y que no han estado exentos de polémica y a veces de beligerancia. Por un lado el juicio lapidario del Cardenal Ratzinger de que una auténtica y verdadera interpretación del Concilio todavía no había comenzado a los veinte años de

46 L. Boeve, "'La vraie réception de Vatican II n’a pas encore commencé”. Joseph Ratzinger, Révélation et autorité de Vatican II", en L'Autorité et les autotités. L'herméneutique théologique de Vatican II, sous la direction de G. Routhier et G. Jobin, (Cerf, Paris, 2010) 47. 
la realización de este y la politización del debate a raíz de los esfuerzos de Roma para llegar a un acuerdo con los discípulos de Lefebvre, el único grupo que lo rechazó explícitamente por considerar que estaba en discontinuidad y ruptura con la tradición de la Iglesia. Por otro la producción y publicación en estos años de dos esfuerzos intelectuales notables de enorme valía para la interpretación del Concilio: la historia del Vaticano II dirigida por G. Alberigo y el comentario alemán dirigido por Hünermann y Hilberath. De telón de fondo el largo pontificado de Juan Pablo II que consideró el Concilio como el gran acontecimiento de gracia y la hoja de ruta, la brújula segura, para orientar a la Iglesia.

Hemos presentado una serie de nuevas aproximaciones que constituyen verdaderos aportes teológicos para interpretar y comprender la significación del acontecimiento conciliar. Todas ellas tienen en común la superación de ciertas tensiones y polaridades que hace que las interpretaciones en conflicto puedan dejar de ser polaridades excluyentes para transformarse en dialécticas productivas. No es necesario oponer a una hermenéutica de la discontinuidad, mala, una hermenéutica de la discontinuidad, buena, pues comprendemos, gracias al propio Benedicto que la hermenéutica de la reforma es justamente la continuidad en la discontinuidad. Es posible por tanto apreciar que el Concilio constituye una novedad en la historia de la Iglesia, que nos obliga a abandonar determinaciones eclesiales que ya no tienen vigencia. No es necesario seguir oponiéndose a la modernidad, a las iglesias protestantes, a la Iglesia Ortodoxa, y a la libertad religiosa. Si el Concilio es como un texto constitucional de la fe se puede dar un paso hacia nuevas figuras de fe y eclesialidad. Tampoco es necesario oponer el carácter pastoral del Concilio a su carácter doctrina. Si pastoralidad es atención a los contemporáneos, en cuanto ellos son los destinatarios de la Palabra de Dios, el único tesoro de la Iglesia, la reforma y la novedad, consisten en una extroversión eclesial que la invita a la doble escucha de la Revelación y de los signos de los tiempos. No es necesario oponer la vuelta a las fuentes que la acerca al evangelio con el aggiornamento que la acerca a los hombres y mujeres de nuestro tiempo. Por último no es necesario oponer el espíritu del concilio a su letra, el acontecimiento a sus textos. Pues la novedad consiste justamente en un nuevo lenguaje, en una nueva retórica, en una nueva manera de hablar, de comunicarse, de dialogar. Con más compasión que condenación (más compasiva, que severa), La hermenéutica de la reforma, las novedades que ella implica, el acercamiento tanto a 
El conflicto de interpretaciones en torno a la recepción del Concilio Vaticano II | 253

la Palabra de Dios como a los contemporáneos, el nuevo lenguaje y la actitud de diálogo que manifiestan los textos del Concilio son frutos preciosos de la segunda etapa de este segundo periodo. Al encontrar en estos criterios hermenéuticos buenas claves para seguir con la recepción del Concilio, ciertamente no se pone fin al conflicto de interpretaciones pero sí a odiosas polaridades que se excluyen mutuamente. 
Resumen: La Iglesia ha estado dedicada durante estos cincuenta años a la recepción del Concilio. No debe extrañarnos que diversas interpretaciones del acontecimiento conciliar y de sus textos entren en conflicto, pues tanto su preparación como su realización estuvieron llenas de ellas. Una periodización teniendo como criterio estos esfuerzos hermenéuticos nos permite distinguir un segundo periodo de "problematización hermenéutica» después del Sínodo extraordinario convocado para celebrar los veinte años. Destacamos algunos hitos clave de este periodo y una serie de nuevas aproximaciones teológicas sobre el Concilio: la de Benedicto XVI con su «hermenéutica de la reforma»; la de Hünermann señalando que se trata de un «texto constitucional de la fe» que se despide de algunas figuras eclesiales anteriores; la de Theobald con el "principio de pastoralidad» como clave; la de O'Malley señalando que es la nueva retórica y un nuevo lenguaje la mayor novedad del Concilio. Aportes que no pondrán fin a los conflictos en la interpretación del Concilio pero sí contribuyen a superar las polaridades excluyentes.

Palabras clave: Concilio Vaticano II, recepción, periodización, nuevas interpretaciones teológicas.

Abstract: The Catholic Church has been working during the last 50 years in the reception of the Second Vatican Council. So, it is not surprising that different interpretations about what happened during the Council and its texts has been in conflicts, because both its preparation and in its sessions were full of different interpretations. We can distinguish several hermeneutical efforts during the reception of the Vatican II. We can identify a period of "hermeneutical problematization" after de extraordinary Sinode of Bishops that took place to commemorate the 20 years of the Council. We can highlight in this period some milestones of this period and several new theological approximations about the Council: Benedict XVI's and its "hermeneutics of the reform"; Hünermann's affirmation that Vatican II is a "constitutional text about our faith" that leaves behind some previous ecclesiastical figures; Theobald's "pastoral principle" as a key; O'Meally's affirmation that the greatest novelty of the Council is a new rhetoric and a new language. Such contributions will not put to an end the conflicts of interpretation of the Council but they will contribute to overcome exclusive polarities.

Keywords: Second Vatican Council, reception, new theological interpretations. 